\section{EL PROCESO DE} CAMBIO

\section{ORGANIZATIVO Y}

LAS

\section{ORGANIZACIONES INTELIGENTES}

\author{
Mg. SABINO TALLA RAMOS
}

\section{INTRODUCCIÓN}

Actualmente estamos asistiendo a una de las olas de cambio más notables en la historia de la humanidad; ahora, estamos ante un nuevo fenómeno de comunicación que está provocando una nueva revolución: Internet, que permite emitir y recibir todo tipo de información independientemente de la distancia y a un costo muy bajo; asimismo los planteamientos sobre las organizaciones han ido evolucionando a la par de las cambiantes perspectivas culturales y socioeconómicas. "El actual es un tiempo de gran agitación empresarial, en el que las instituciones antiguas $y$ formales se encuentran repentinamente con que tienen que volverse muy flexibles" (Drucker, 1993). Así pues, las organizaciones actuales están sometidas a un proceso de cambio, este ritmo de cambio hace que el nuevo valor de las organizaciones sea la adaptación: adaptarse para sobrevivir. Una de las respuestas a esta situación actual son las “Organizaciones Inteligentes", que plantea soluciones:

- Frente a la variedad: unificación.

- Frente al cambio: capacidad de aprendizaje.

- Frente a la necesidad de conseguir mayor calidad: trabajo en equipo.

Las organizaciones hoy en día tienden a ser organizaciones del conocimiento. Las organizaciones que cobrarán relevancia en el futuro serán las que descubran cómo aprovechar el entusiasmo y la capacidad de aprendizaje de la gente en todos los niveles de la organización, al respecto Arie de Geus advierte que: "La capacidad de aprender puede llegar a ser nuestra única ventaja competitiva".

\section{EL PROCESO DE CAMBIO ORGANIZATIVO}

En ocasiones el cambio se da virtualmente de manera forzada contra la voluntad de las organizaciones, mientras que en otras ocasiones el cambio es algo abiertamente buscado y abrazado.

El cambio organizacional puede definirse como "la modificación y transformación de la forma de modo que sobreviva mejor en el ambiente".

Las organizaciones están cambiando constantemente. Los cambios en las organizaciones forman ahora una parte de la vida normal.

La organización que sobrevive, es aquella que es capaz de hacer las adaptaciones que le permiten vencer $\mathrm{o}$, por lo menos, coexistir con sus competidores. Estas adaptaciones son los cambios organizacionales.

El mundo se mueve cada vez más deprisa, hemos de responder desde una capacidad de reacción cada vez más ágil.

El cambio, cuando es para mejorar y ofrece la posibilidad de que las personas se desarrollen. es siempre algo positivo, no debemos mirar el proceso de cambio como una amenaza, sino como un reto. 
Para cambiar -y mantener el proceso de cambio-hace falta decisión. compromiso y persistencia. No es sólo decirlo, ni siquiera desearlo. Hay que transformarlo en acciones.

La premisa de todas las nuevas estrategias, es el hecho de que hoy en día las empresas necesitan estar organizadas para el cambio constante.

Para prosperar hoy en día, las personas tienen que dominar la manera de aprender con rapidez una amplia gama de habilidades.

Pasar por este proceso es parecido a la remodelación total de una cocina. Para lograr el resultado que se desea, primero hay que desmontar la cocina vieja, con lo cual queda al descubierto el vacío y gran parte de la estructura básica. Entonces se comienzan a colocar los nuevos muebles y utensilios de manera que combinen armoniosamente. Una vez que se añaden los toques finales, puede uno volver a ocuparla y sentirse cómodo y productivo en ella. La remodelación siempre consume más tiempo del que se pensó y cuesta más de lo que se calculó.

A menudo, el cambio no es otra cosa que una sencilla modificación de la tecnología o de las relaciones jerárquicas. Pero cuando una compañía tiene que hacer frente a un cambio mayor, o una crisis grave exige una respuesta, lo que en realidad cambia es la "cultura corporativa"; es decir, la manera como la empresa está haciendo las cosas. El desafío consiste en aumentar la productividad y simultáneamente, conducir al grupo hacia una nueva dirección.

\section{Normas básicas durante el cambio:}

1. Tener una buena razón para hacer el cambio.

2. Involucrar a las personas en el cambio.

3. Encomendar el proceso a una persona respetada.

4. Formar equipos para el manejo de la transición.

5. Dar capacitación sobre nuevos valores y comportamientos.

6. Obtener ayuda de una persona fuera de la organización.

7. Establecer símbolos del cambio.

8. Reconocer y recompensar a las personas.

ORGANIZACIONES Y LA SOCIEDAD DEL CONOCIMIENTO

La revolución del conocimiento engendrará una nueva sociedad:

La sociedad del conocimiento. Un modo de interpretar los cambios acelerados en la década del ochenta, consiste en verlos simplemente como otro aspecto de una revolución tecnológica centrada en la innovación y la creciente popularidad de las comunicaciones informáticas.

Con esa perspectiva limitada, el cambio se puede explicar como otro ejemplo más del incesante desfile de hallazgos tecnológicos que han contribuido a definir la sociedad moderna desde que comenzó la revolución industrial. La verdadera aportación de estas innovaciones consiste en alentar el incremento de la oferta de valor-conocimiento creativo.

\section{ORGANIZACIONES: DE LO ANÓNIMO A LO PERSONALIZADO}

El hecho de que los medios de producción de valor-conocimiento estén inextricablemente asociados con la gente, vaticina grandes cambios en las organizacio- 
nes que manejan la producción. Las organizaciones de la sociedad industrial, se formaban en torno a un núcleo de instalaciones mecanizadas de gran escala y con el tiempo dichas organizaciones se volvieron características de la actividad económica. Ello llevó al desarrollo de la "sociedad anónima".

Pero cuando los principales componentes de los medios de producción son el conocimiento. la experiencia y la sensibilidad propios de la creación de valorconocimiento, la existencia del proceso productivo depende del individuo, así que parte del conocimiento, la experiencia y la sensibilidad se han vuelto propiedad común, lo cual también puede ocurrir con otros activos, consecuentemente las organizaciones de la sociedad del conocimiento dependerán de las personas que constituyan sus medios de producción y serán mucho más fluidas que las organizaciones de la sociedad industrial

En una organización que depende de la capacidad y el carácter de la personalidad de la cual depende la organización misma, esa personalidad central desempeñará un papel central. Aún se necesitarán muchos conocimientos y aptitudes específicas, y los méritos de la diversificación serán decisivos en una sociedad del conocimiento, que probablemente posea un entorno social más complejo que el de la sociedad industrial.

Las tendencias recientes en gestión se apartan de la estructura.jerárquica vertical y adoptan un modelo holográfico con flujo de información multidimensional. habrá ciertos límites para la escala en que una organización holográfica puede operar eficientemente, pues el trabajo de las personas que conforman el núcleo se volverá más multidimensional y polifacético.

\section{ORGANIZACIONES INTELIGENTES}

La organización inteligente llamada también organización que aprende o organización autocualıficante. Denominación que describe a aquellas empresas que están involucradas en un proceso de cambio y transformación mediante el aprendizaje, existen dos líneas complementarias: el enfoque europeo y el enfoque de Estados Unidos.

La aportación europea más consistente es la de John Burgoyne, Mike Pedler y Tom Boydell; que desde 1976 definen "La organización que aprende es aquella que facilita el aprendizaje de todos sus miembros y experimenta en sí misma una transformación continua". En cualquier organización existen tres niveles o grados de aprendizaje efectivo:

1. Aprendizaje prescriptivo en la que la organización memoriza.

2. Aparece cuando la organización aprende a adaptarse frente a las exigencias cambiantes del mercado y del sistema social y político.

3. Aprendizaje transformacional en la que la organización aprende a desarrollarse.

El enfoque norteamericano viene representado por Peter Senge, quien afirma que para que una organización sea una organización que aprende, es necesario que aprenda a aprender. Lograr el dominio de este proceso implica conocer y aplicar cinco disciplinas:

1). El pensamiento sistémico.

2). El dominio personal.

3). Los modelos mentales.

4). La visión compartida.

5). El aprendizaje en equipo. 
Las organizaciones que aprenden utilizan fundamentalmente el aprendizaje colectivo, requiere el proceso interactivo de todos los integrantes. Las organizaciones que aprenden favorecen una forma de aprender consciente basada en el cuestionamiento sistemático de lo que se está haciendo, cómo se hace, con qué propósito y por qué, enfocan el aprendizaje de forma multilateral y variado buscando de manera consciente afrontar paradojas y contradicciones.

El significado básico de organización inteligente, es que se trata de una organización que aprende y continuamente expande su capacidad para crear su futuro. El aprendizaje para la supervivencia, lo que a menudo se llama aprendizaje adaptativo es importante y necesario. Pero una organización inteligente conjuga el aprendizaje adaptativo con el aprendizaje generativo, un aprendizaje que aumenta nuestra capacidad creativa.

“Organizaciones inteligentes", organizaciones donde la gente expande continuamente su aptitud para crear los resultados que desea, donde se cultivan nuevos y expansivos patrones de pensamiento, donde la aspiración colectiva queda en libertad, y donde la gente continuamente aprende a aprender en conjunto. Las organizaciones inteligentes son un instrumento de gran ayuda para organizar y conducir acciones de vigilancia, prevención y control. Son tecnología de punta en la administración; permiten generar esquemas del comportamiento de estructuras y políticas de organizaciones, describen sistemáticamente problemas e integran modelos computarizados.

Es adquirir y aplicar los conocimientos, técnicas, valores, creencias y actitudes que incrementan la conservación, el crecimiento y el progreso de la organización.

\section{DISCIPLINAS DE LA ORGANIZACIÓN INTELIGENTE}

Una disciplina es una senda de desarrollo para adquirir ciertas actitudes o competencias, es un corpus teórico y técnico que se debe estudiar y dominar para llevarlo a la práctica.

Lo que distinguirá fundamentalmente las organizaciones inteligentes de las tradicionales y autoritarias "organizaciones de control" será el dominio de ciertas disciplinas básicas. en la actualidad, cinco nuevas tecnologías de componentes convergen para innovar las organizaciones inteligentes.

\section{Pensamiento sistémico}

Los negocios y otras empresas humanas también son sistemas. El pensamiento sistémico es un marco conceptual, un cuerpo de conocimientos y herramientas que se ha desarrollado en los últimos cincuenta años, para que los patrones totales resulten más claros, y para ayudarnos a modificarlos.

El pensamiento sistémico es la quinta disciplina, integra las demás disciplinas, fusionándolas en un cuerpo coherente de teoría y práctica.

Es una disciplina para ver totalidades. Es un marco para ver interrelaciones en vez de cosas, para ver patrones de cambio en vez de "instantáneas" estáticas.

Es una disciplina para ver las "estructuras" que subyacen a las situaciones complejas, y para discernir cambios de alto y bajo apalancamiento.

La esencia de la disciplina de pensamientos sistémico radica en un cambio de enfoque: ver las interrelaciones en vez de 


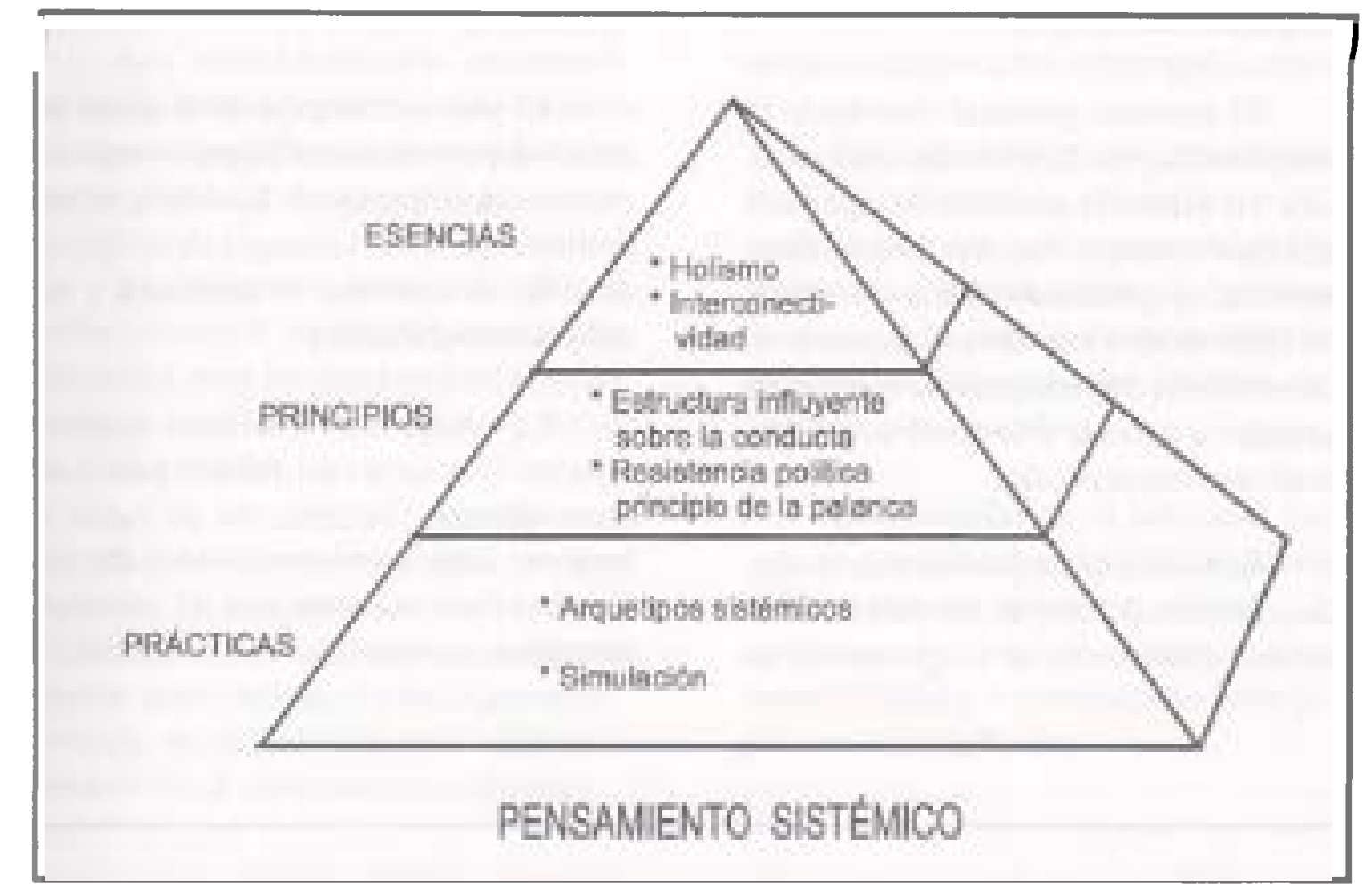

las concatenaciones lineales de causa-efecto; y ver procesos de cambio en vez de "instantáneas".

En las organizaciones inteligentes, el pensamiento sistémico se transforma en un agente cotidiano activo, que continuamente revela cómo creamos nuestra realidad, sólo cuando los gerentes comienzan a pensar en términos de arquetipos sistémicos. La clave del pensamiento sistémico es la palanca: hallar el punto donde los actos y modificaciones en estructuras puedan conducir a mejoras significativas y duraderas. A menudo la palanca sigue el principio de la economía de medios, buscando el lugar donde los mejores resultados no provienen de esfuerzos en gran escala sino de actos pequeños y bien focalizados.

El arte del pensamiento sistémico consiste en ver a través de la complejidad las estructuras subyacentes que generan el cambio.

\section{Dominio Personal}

La gente con alto nivel de dominio personal es capaz de alcanzar coherentemente los resultados que más le importan: los consigue consagrándose a un aprendizaje incesante.

El dominio personal es la disciplina que permite aclarar y ahondar continuamente nuestra visión personal. concentrar las energías, desarrollar paciencia y ver la realidad objetivamente. En cuanto tal, es una piedra angular de la organización inteligente, su cimiento espiritual.

Aquí interesan ante todo las conexiones entre aprendizaje personal y aprendizaje organizacional. los compromisos recíprocos entre individuo y organización, el espíritu especial de una empresa constituida por gente capaces de aprender.

Las organizaciones sólo aprenden a 
través de individuos que aprenden, es la disciplina del crecimiento.

El dominio personal trasciende la competencia y las habilidades, aunque se basa en ellas. Trasciende la apertura espiritual, aunque requiere crecimiento espiritual. Significa abordar la vida como una tarea creativa y no meramente reactiva. La esencia del dominio personal consiste en aprender a generar y sostener la tensión creativa en nuestras vidas.

Es una disciplina que dura toda la vida. Las gentes con alto nivel de dominio personal son muy conscientes de su ignorancia, su incompetencia, sus zonas de crecimiento. $\mathrm{Y}$ sienten una profunda confianza en sí mismas.

El pleno desarrollo de la gente es esencial para alcanzar nuestra meta de excelencia empresarial. La visión es un destino específico, la imagen de un futuro deseado, es concreta, es intrínseca y no relativa, es multifacética.

La perspectiva sistémica ilumina aspectos más sutiles del dominio personal, especialmente: integración de razón e intuición; visión continuamente intensificada de nuestra conexión con el mundo; compasión; compromiso con la totalidad.

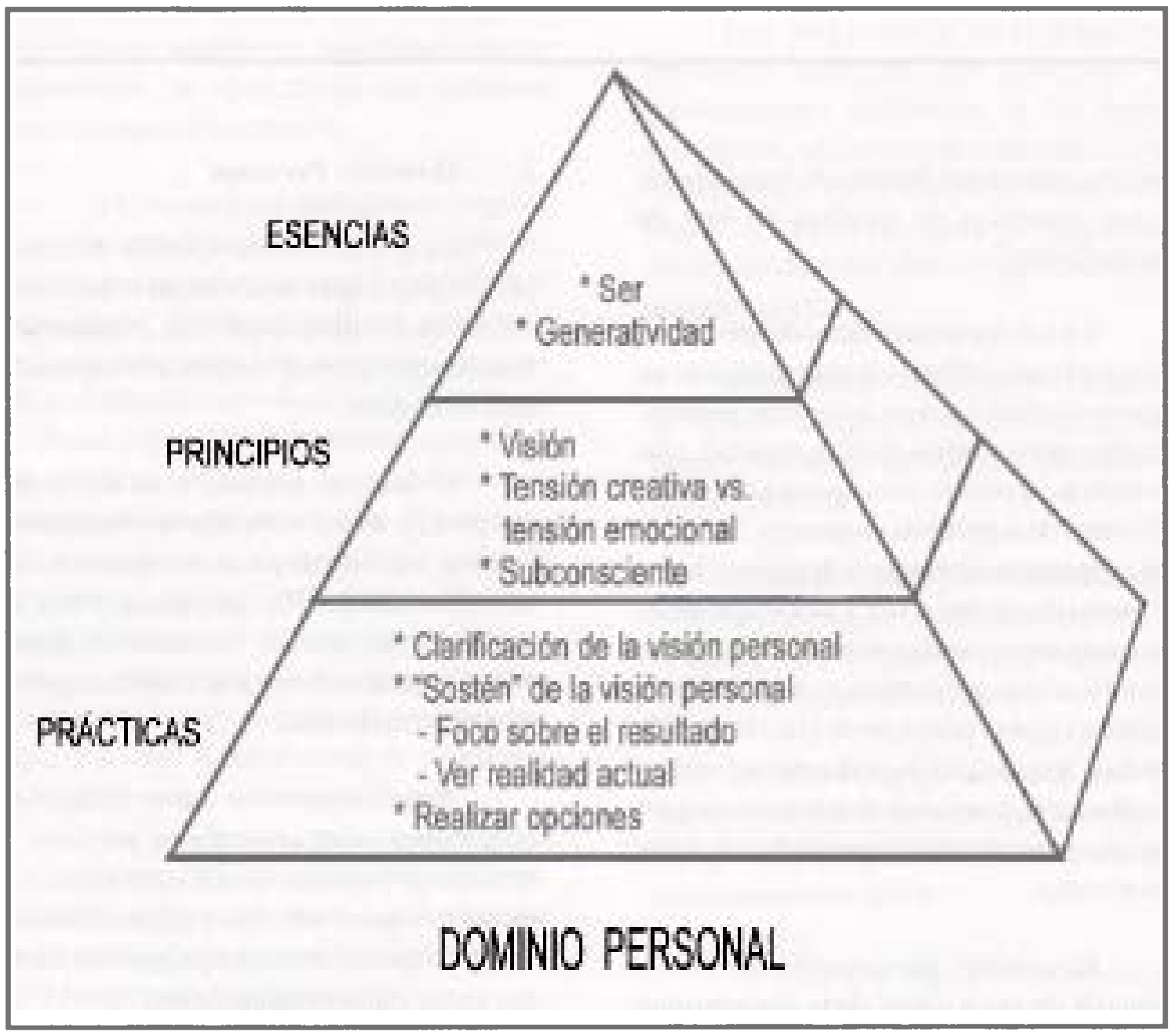




\section{Modelos Mentales}

Los "modelos mentales" son supuestos hondamente arraigados, generalizaciones e imágenes que influyen sobre nuestro modo de comprender el mundo y actuar.

Muchas percepciones acerca de mercados nuevos o de prácticas organizacionales anticuadas no se llevan a la práctica porque entran en conflicto con poderosos y tácitos modelos mentales.

La disciplina de manejar modelos mentales -el afloramiento, verificación y perfeccionamiento de nuestras imágenes internas acerca del funcionamiento del mundopromete ser una decisiva innovación en la construcción de organizaciones inteligentes.
Pueden ser simples generalizaciones o teorías complejas, son activos, pues moldean nuestros actos, son simplificaciones.

En la organización inteligente, el nuevo dogma consistirá en visión, valores y modelos mentales. Las empresas saludables serán las que puedan sistematizar maneras de reunir a la gente para desarrollar los mejores modelos mentales posibles para enfrentar toda situación.

El desarrollo de la habilidad para trabajar con modelos mentales, supone el aprendizaje de aptitudes nuevas y la implementación de innovaciones institucionales que contribuyen a llevar a la práctica estas aptitudes.

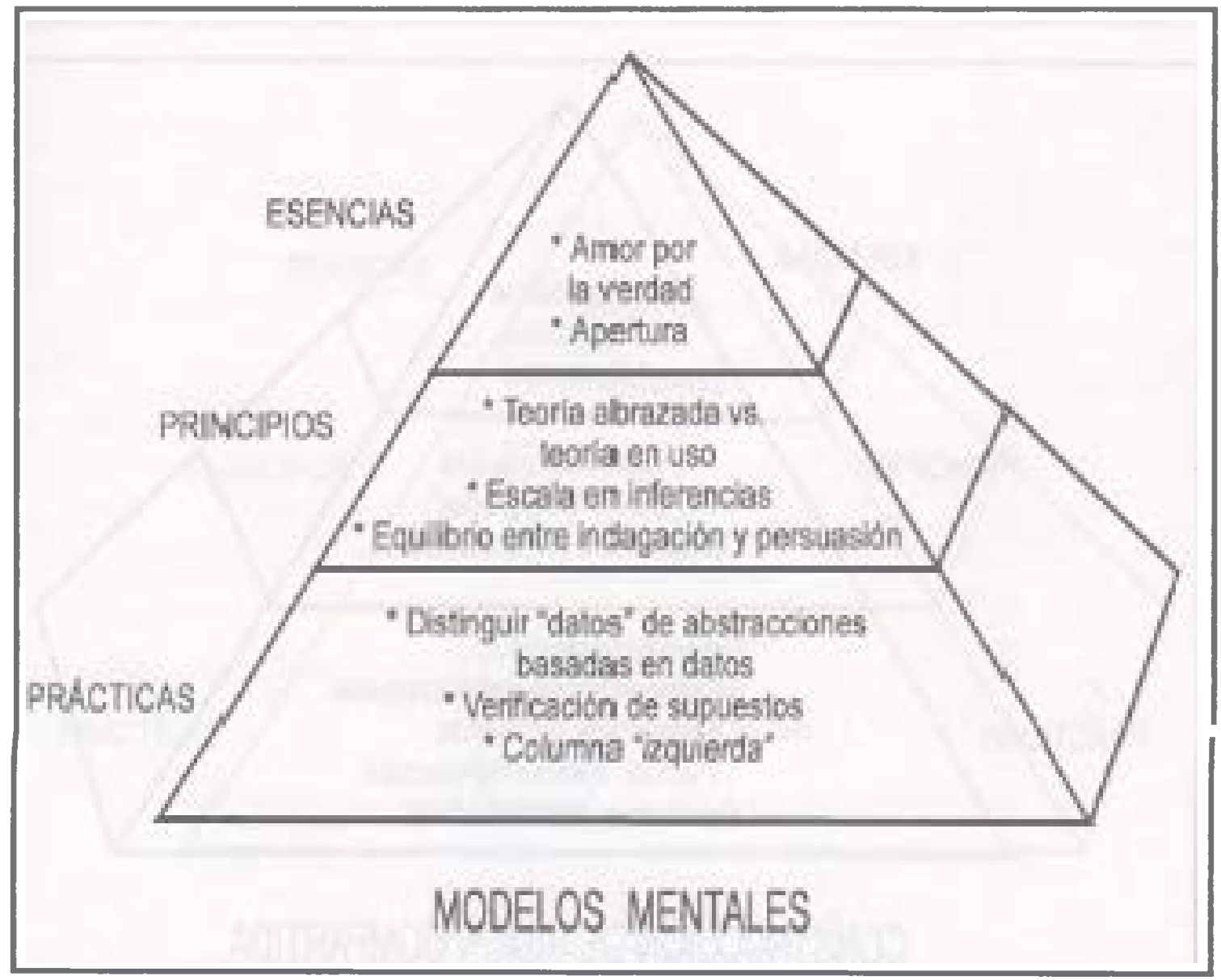


Los modelos mentales arraigados frenan los cambios que podrían derivar del pensamiento sistémico, el pensamiento sistémico es igualmente importante para trabajar eficazmente con modelos mentales.

\section{Visión Compartida}

La práctica de la visión compartida supone aptitudes para configurar "visiones del futuro" compartidas que propicien un compromiso genuino antes que mero acatamiento.

Las visiones compartidas son imágenes que lleva la gente de una organización. Crean una sensación de vínculo común que impregna la organización y brinda coherencia a actividades dispares. Cuando la gente comparte una visión está conectada. vinculada por una aspiración común.
La visión compartida es vital para la organización inteligente porque brinda concentración y energías para el aprendizaje. En la actualidad, "visión" es un concepto familiar en el liderazgo empresarial.

Una visión compartida es el primer paso para permitir que gente que se profesaba mutua desconfianza comience a trabajar en conjunto. Crea una identidad común.

La visión compartida alienta la experimentación y el deseo de correr riesgos. Está arraigado en el conjunto de valores, intereses y aspiraciones de un individuo. El interés genuino en una visión compartida está arraigado en visiones personales.

La visión pinta la imagen de lo que deseamos crear. El pensamiento sistémico

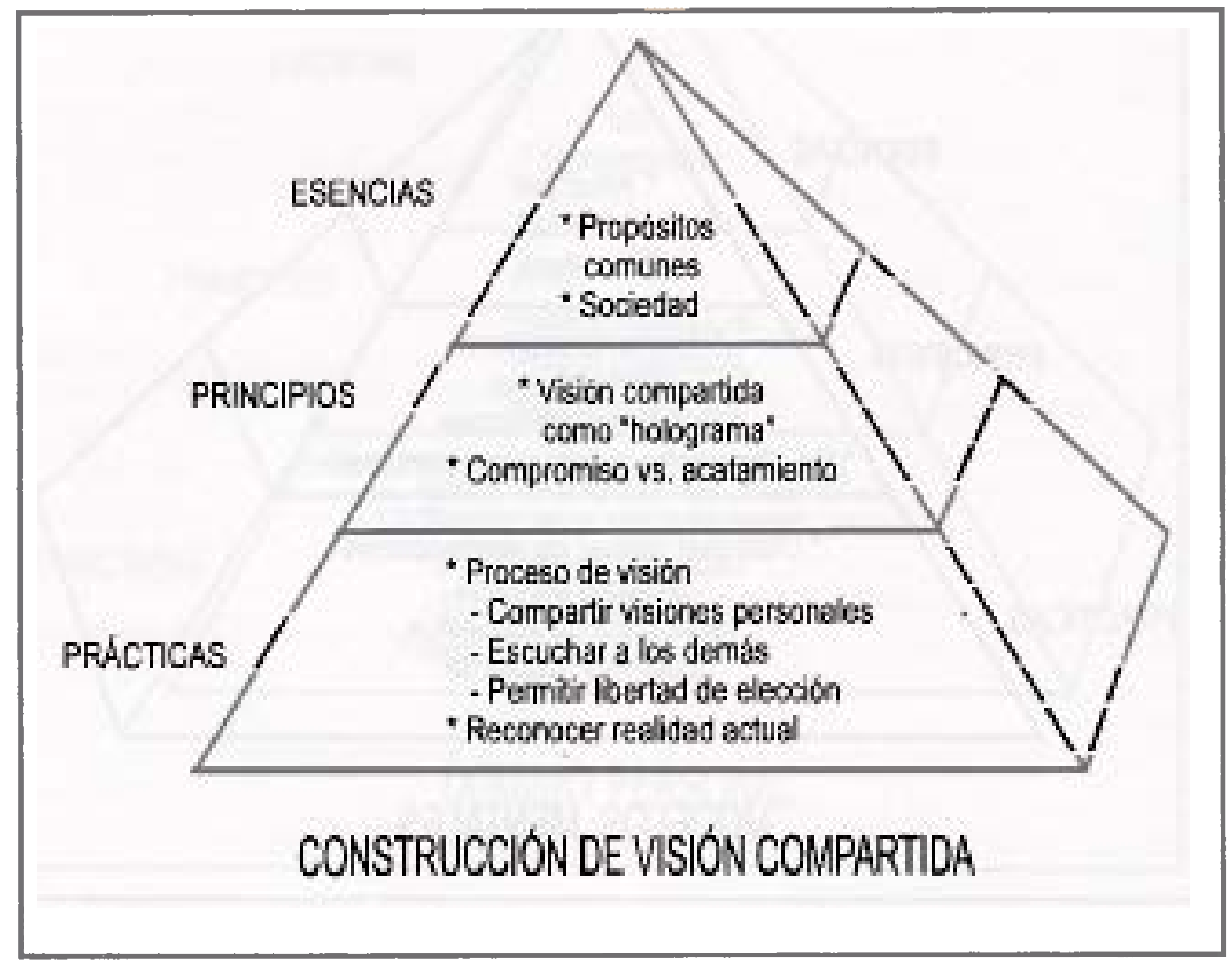


revela cómo hemos creado lo que tenemos ahora.

\section{Aprendizaje en Equipo}

La disciplina del aprendizaje en equipo comienza con el diálogo. El aprendizaje en equipo es vital, porque la unidad fundamental de aprendizaje en las organizaciones modernas no es el individuo sino el equipo.

El aprendizaje en equipo es el proceso de alinearse y de desarrollar la capacidad de un equipo para crear los resultados que sus miembros realmente desean. Se construye sobre la disciplina de desarrollar una visión compartida. También se construye sobre el dominio personal.

El aprendizaje en equipo tiene tres dimensiones críticas: necesidad de pensar agudamente sobre problemas complejos, necesidad de una acción innovadora, coordinada y el papel de los miembros del equipo en otros equipos.

La disciplina del aprendizaje en equipo implica dominar las prácticas del diálogo y la discusión, las dos maneras en que conversan los equipos; también implica aprender a afrontar creativamente las poderosas fuerzas que se oponen al diálogo y la discusión productivas.

Un equipo comprometido con el aprendizaje no sólo debe decir la verdad acerca de lo que ocurre "afuera", en el ámbito de los negocios, sino "adentro", en el interior del equipo.

La perspectiva y las herramientas del pensamiento sistémico son cruciales para el

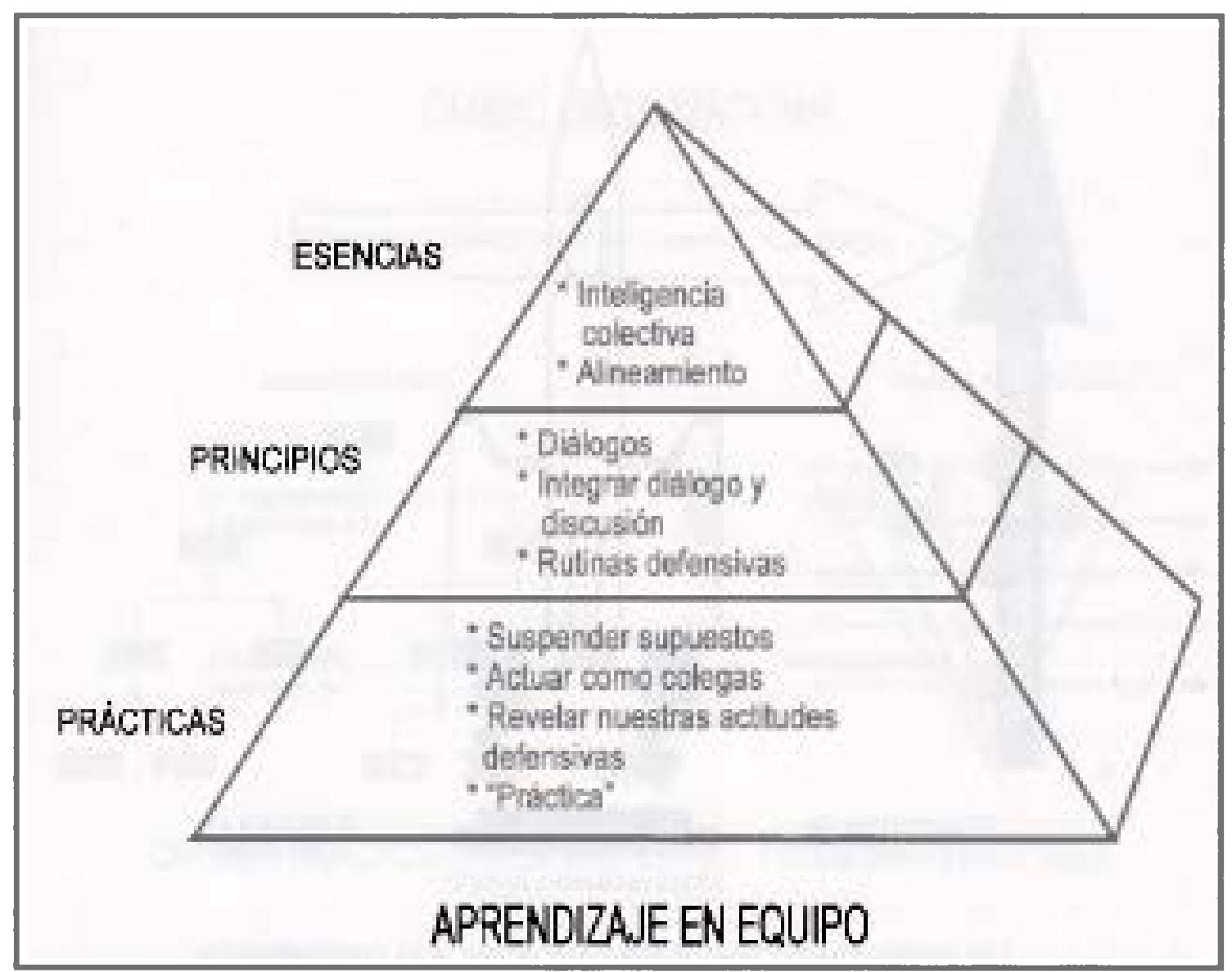


aprendizaje en equipo. Se puede abordar cada una de las cinco disciplinas en tres niveles:

- prácticas: qué hacer;

- principios: ideas rectoras y conceptos;

- esencias: el estado de ser de quienes tienen un gran dominio de la disciplina.

Las prácticas son las actividades en que los practicantes de la disciplina concentran el tiempo y las energías. Cada dis- ciplina tiene principios subyacentes que representan la teoría que justifica las prácticas. El tercer nivel es el de las esencias, consiste en ese estado de ser que llegan a experimentar naturalmente los individuos o grupos que poseen un al to nivel de dominio de las disciplinas. Las disciplinas de la construcción de la visión compartida y del aprendizaje en equipo. difieren de las otras tres porque son inherentemente colectivas. Las prácticas son actividades grupales. Los principios se deben com-

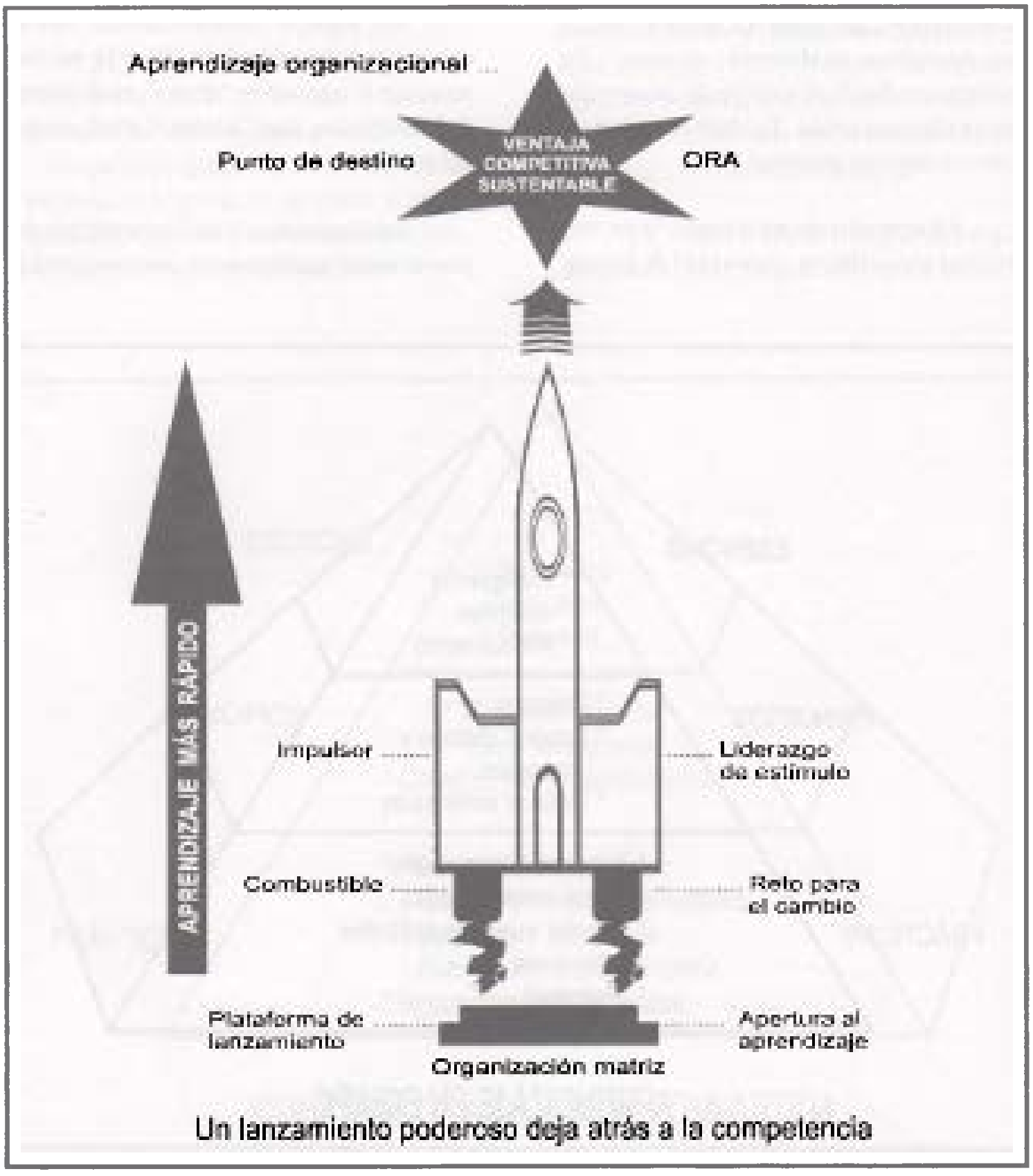


prender en grupo. Y las esencias son estados de ser que se experimentan colectivamente.

\section{EL APRENDIZAJE}

Definiciones de aprendizaje aparecen profusamente en la literatura actual. De entre ellas la explicación más común es la de definir al aprendizaje como un cambio relativamente permanente de la conducta producto de una práctica convenientemente reforzado o de una experiencia significativa.

Considerar en profundidad el aprendizaje implica comenzar a comprenderlo de forma diferente a la habitual. La aportación de Peter Hawkins, nos parece una síntesis clara:
A. Del aprender datos al aprendizaje dialogante.

B. Del aprendiz como un recipiente al aprendizaje co-creativo.

C. Del aprender que reciben en las personas al aprendizaje que también reside en los modelos sistémicos.

D. Del aprender de forma simple y lineal al aprendizaje cíclico y complejo.

E. Del aprender como un medio para lograr un fin al aprendizaje como motor y corazón de todo lo que las personas hacen a lo largo de toda la vida.

Mediante el aprender consciente se adquiere un tipo de sabiduría que orienta la acción de las personas desde un sentido racional en el conjunto de toda la vida.

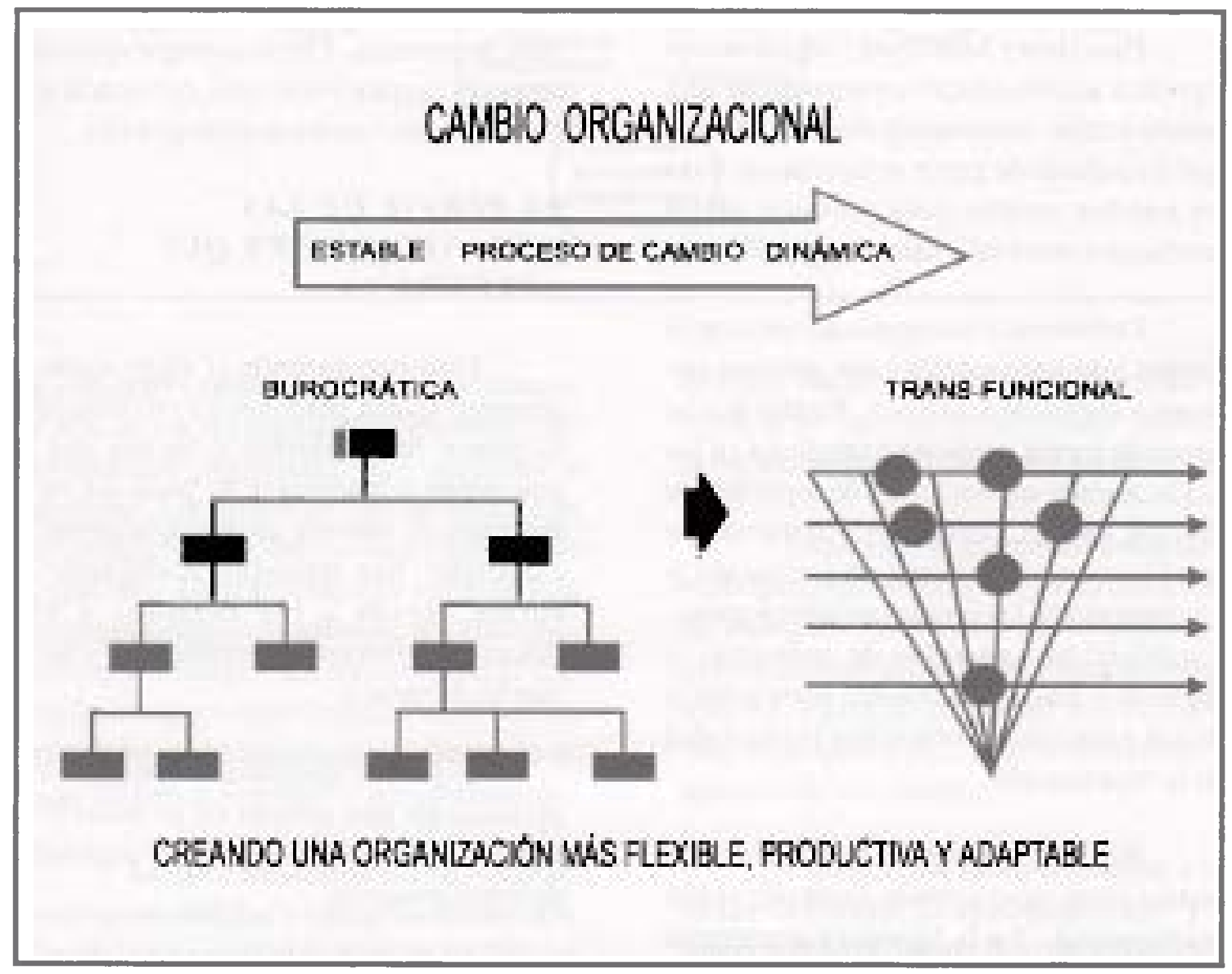


TIPOS DE APRENDIZAJE ORGANIZACIONAL

En una empresa ocurre una extensa gama:

- Aprendizaje de tareas

- Aprendizaje sistemático

- Aprendizaje cultural

- Aprendizaje del liderazgo

- Aprendizaje de equipo

- Aprendizaje estratégico

- Aprendizaje empresarial

- Aprendizaje reflexivo

- Aprendizaje de la transformación

\section{LAS ORGANIZACIONES}

Peter Drucker define las organizaciones "como un grupo humano de especialistas que trabajan unidos en la consecución de una tarea común" (Drucker, 1993).

Para Henry Mintzberg "organización significa acción colectiva para realizar una misión común, una manera elegante de decir que un puñado de gente se ha reunido bajo un nombre común para producir algún producto o servicio" (Mintzberg, 1991).

Definimos a las organizaciones como grupos humanos estables que generan sus propias reglas de actuación. Reglas que se basan de forma explícita o implícita en las explicaciones que en forma de argumentos lógicos, teorías, conceptos y opiniones se establecen en el proceso de formación y crecimiento de las propias organizaciones. Establece un conjunto de creencias y supuestos básicos llamados principios y llegan a constituir la esencia y la identidad de la organización.

Pueden contemplarse desde un sentido institucional como también desde una visión instrumental. En la literatura académica aparecen dos posturas antagónicas respecto a la concepción de las organizaciones: la teoría de las interacciones y la teoría de los sistemas. Una organización es tanto una construcción social como un sistema, siendo relevante cómo las personas que dan forma a la organización perciben y experimentan su propia realidad.

\section{CONSTRUIR UNA ORGANIZACIÓN QUE APRENDE}

Construir una organización que aprende, significa estar hablando de una organización que cambia mediante el proceso de aprender y lo hace de forma colectiva mediante la interacción de las personas que configuran la organización, efectúan los procesos y el conjunto de actividades de forma distinta.

El problema consiste en transformar los conocimientos personales en sabiduría capaz de ser utilizada por la organización para que aprenda. Ello se consigue aplicando cuatro principios esenciales: comunicación, participación, consenso e integración.

\section{EL PERFIL DE LAS ORGANIZACIONES QUE APRENDEN}

Permiten cumplir el viejo sueño..., generan riqueza, perduran más en el tiempo, disponen de productos o bienes que se consumen y mantienen su posición en el mercado. Se identifican dos características esenciales: han aprendido a adaptarse de forma rápida a los cambios y han desarrollado un estilo propio de ser y hacer que les diferencia.

Es posible identificar los principios de aprendizaje que aplican en su manera de actuar y el camino que siguen en su proceso de transformación.

\section{* Comparten una visión: el futuro}




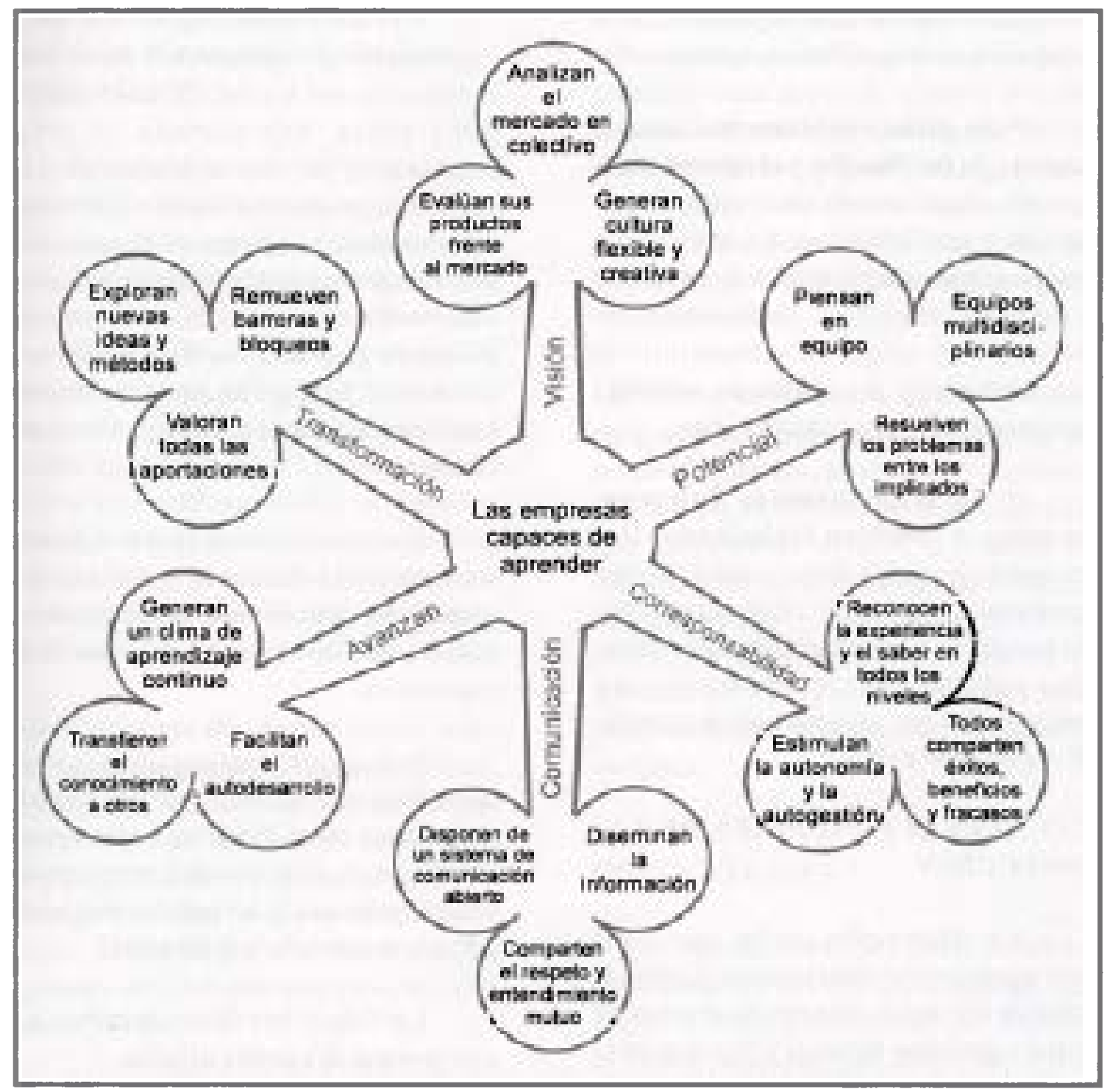

se construye cada día. Es la consecuencia de uno de los principios fundamentales del aprendizaje organizacional: aprender a aprender. Las empresas que aprenden han recorrido un largo camino hasta llegar a ser lo que son. Una empresa que aprende está continuamente expandiendo su capacidad para crear su futuro. La construcción de una visión compartida es importante desde un principio porque impulsa una orientación de largo plazo y el imperativo del aprendizaje.

* Actúan mediante un sistema de corresponsabilidad y compromiso mutuo. Tienen como pilar el trabajo de los líderes cuando ejercen su influencia infundiendo energía para la creatividad y ayudan a compartir la visión, creando valores compartidos y estimulando el aprendizaje.

* Creen en su potencial conjunto: trabajan, aprenden y mejoran en el seno de equipos. Ponen en marcha proyectos que facilitan el aprendizaje grupal al tiempo que se trabaja, trabajan en equipos multidisciplinares complementarios, el aprendizaje es colectivo.

\section{* Comparten la información y las} ideas: utilizan la comunicación y el intercambio de forma flexible y continua. Desarrollan una estructura de funcionamiento 
en la que la comunicación de doble vía es el vehículo para desarrollarse y aprender.

* Avanzan rápidamente: usan el soporte, la facilitación y el aprendizaje. Los directores invierten la mayor parte de su esfuerzo en facilitar que los individuos y grupos adquieran altos niveles de autonomía y capacidad de gestión. Están entrenados hacia crear, adquirir y transferir el conocimiento y modifican su conducta integrando los nuevos conocimientos.

* Se transforman: innovan, inventan y cambian trabajando. Hay búsqueda de nuevas ideas, crean al tiempo que trabajan. El cambio rápido y constante del mercado y la mejora continua son valores que comparten y que actúan de motor que estimula el poner a prueba nuevas maneras de organizar el trabajo.

\section{LAS NUEVAS FUNCIONES DE LA DIRECCIÓN}

La Dirección debe prevenir contingencias y reducir riesgos, facilitar la labor de los demás miembros, orientar su trabajo, gestionar recursos y procurar tener una economía sana con la que se pueda funcionar adecuadamente, evaluar procesos y resultados y establecer sistemas eficaces de participación y comunicación que permitan adoptar decisiones acertadas dentro de su contexto.

El reconocimiento de la importancia de variables como la cultura, la diversidad, el entorno, el cambio, la incertidumbre y la interdependencia justifican que la Dirección se centre en perspectivas holísticas.

La tarea básica de la Dirección es lograr que las personas situadas en todos los niveles puedan aprender, y que el aprendizaje permita tanto la adquisición de nuevos conocimientos como su aplicación.
Un directivo competente en la organización que aprende debe facilitar una ordenación del trabajo funcionalmente integradora, que permita el grupo colaborativo, las islas de producción y los sistemas de producción flexibles. Debe crear oportunidades, apoyar el crecimiento individual y colectivo, recompensar la innovación, favorecer la comunicación informal, potenciar la dedicación a la innovación, proteger los equipos y celebrar los éxitos en la línea de las organizaciones creativas.

Los gerentes de alto nivel deben dar autoridad a los esfuerzos dirigidos al cambio y apoyarlo activamente participando de manera ostensible en el proceso de su implantación.

Conseguir una organización en aprendizaje permanente exige, por otra parte, fomentar un clima donde crear visiones sea seguro para la gente, donde la investigación y el compromiso con la verdad sean la norma y donde se estimula la superación.

Los líderes que deban de enfrentarse a un proceso de cambio deberán:

a) Comprender que el cambio fundamental sólo se da con gran cantidad de esfuerzo y de tiempo.

b) Convencerse de que es necesario ser detallistas y colocar cimientos sólidos para el cambio.

c) Invertir su propio tiempo y energía en el nuevo proceso.

d) Modelar el proceso de aprendizaje que precisa la organización.

e) Manejar con eficacia la complejidad e incertidumbre del proceso de cambio.

f) Realizar un liderazgo de apoyo.

g) Comprender la importancia de enlazar la energía y entusiasmo de los miembros de la organización con el esfuerzo del cambio. 
¿QUÉ SE REQUIERE PARA

\section{LIDERAR UNA ORGANIZACIÓN INTELIGENTE?}

Las organizaciones inteligentes exigen una nueva perspectiva del liderazgo. La nueva visión del liderazgo en las organizaciones inteligentes se centra en tareas más sutiles e importantes, los líderes son diseñadores, mayordomos y maestros. Son responsables de construir organizaciones donde la gente expande continuamente su aptitud para comprender la complejidad, clarificar la visión y mejorar los modelos mentales compartidos, es decir, son responsables de aprender; esta nueva perspectiva es vital. Los líderes que son diseñadores, mayordomos y maestros, llegan a versu tarea fundamental con sencillez.

- El líder como diseñador. La tarea del líder como diseñador incluye las políticas, estrategias y "sistemas" de la organización. El diseño es, por naturaleza, una ciencia integradora porque el diseño requiere lograr que algo funcione en la práctica; la tarea crucial de diseño para los líderes de las organizaciones inteligentes también concierne a la integración.

La tarea crucial para los líderes de organizaciones inteligentes se relaciona con la integración de la visión, los valores, el propósito, el pensamiento sistémico y los modelos mentales o, más ampliamente, la integración de todas las disciplinas del aprendizaje. La función del líder consiste en diseñar los procesos de aprendizaje por los cuales la gente de la organización puede abordar productivamente situaciones críticas, y desarrollar su dominio de las disciplinas de aprendizaje.

- El líder como mayordomo. El mejor modo de apreciar al "líder como mayordomo" en el contexto de la construcción de organizaciones inteligentes es ver cómo los in- dividuos comprometidos con esa tarea describen su sentido del propósito; en la organización todos deben dominar el ciclo de pensamiento, acción, evaluación y reflexión. De lo contrario no hay aprendizaje válido. Ser el mayordomo de una visión altera la relación entre la visión y el líder. Ella deja de ser una pertenencia para transformarse en una vocación.

- El líder como maestro. Su tarea consiste en ayudar a la gente a ver la realidad de modo más preciso, penetrante y por tanto, potenciador. Los líderes pueden influir para que las personas encaren la realidad en cuatro niveles: hechos, patrones de conducta, estructuras sistémicas y una "historia de propósito"; es alguien que alienta el aprendizaje. ayuda a los integrantes de la organización a desarrollar una comprensión sistémica.

\section{CONCLUSIONES}

1. Las organizaciones hoy en día, tienden a ser organizaciones del conocimiento. Las organizaciones que cobrarán relevancia en el futuro serán las que descubran cómo aprovechar el entusiasmo y la capacidad de aprendizaje de la gente en todos los niveles de la organización, al respecto Arie de Geus advierte que: "La capacidad de aprender puede llegar a ser nuestra única ventaja competitiva".

2. Se adoptan y aplican los conocimientos, técnicas, valores, creencias y actitudes que incrementan la conservación, el crecimiento y el progreso de la organización.

3. Las organizaciones inteligentes se caracterizan por el desarrollo de cinco disciplinas que se aprenden: El pensamiento sistémico, el dominio personal. los modelos mentales, la visión compartida y el aprendizaje en equipo. 
4. Las disciplinas de la construcción de la visión compartida y del aprendizaje en equipo difieren de las otras tres porque son inherentemente colectivas. Las prácticas son actividades grupales. Los principios se deben comprender en grupo. Y las esencias son estados de ser que se experimentan colectivamente.

5. Construir una organización que aprende, significa estar hablando de una organización que cambia mediante el proceso de aprender y lo hace de forma colectiva mediante la interacción de las personas que configuran la organización, efectúan los procesos y el conjunto de actividades de forma distinta.

6. Un directivo competente en la organización que aprende debe facilitar una ordenación del trabajo funcionalmente integradora, que permita el grupo colaborativo, las islas de producción y los sistemas de producción flexibles. Debe crear oportunidades, apoyar el crecimiento individual y colectivo, favorecer la comunicación informal, recompensar y potenciar la dedicación a la innovación, proteger los equipos y celebrar los éxitos en la línea de las organizaciones creativas.

7. Las organizaciones inteligentes exigen una nueva perspectiva del liderazgo. La nueva visión del liderazgo en las organizaciones inteligentes se centra en tareas más sutiles e importantes, los líderes son diseñadores (diseñar los procesos de aprendizaje por los cuales la gente de la organización pueda abordar productivamente situaciones críticas, y desarrollar un dominio de las disciplinas de aprendizaje). mayordomos (ver cómo los individuos comprometidos con esa tarea describen su sentido del propósito), y maestros (es alguien que alienta el aprendizaje).

\section{BIBLIOGRAFÍA}

ARBÚES, $M$.

1997: El perfil de las organizaciones que aprenden, Alta Dirección. Enero-febrero

DRUCKER, $\mathrm{P}$.

1993: La sociedad post capitalista. Grupo Editorial Norma, Colombia.

GAIRÍN, J.

1997: La dirección en los procesos de aprendizaje colectivo. Alta Dirección. Enero-febrero

GUNS, B. 1996: Aprendizaje organizacional, Prentice Hall, México.

HALL, R. 1996: Organizaciones. Prentice Hall, México.

SAKAIYA,T.

1995: Historia del futuro. La sociedad del conocimiento. Editorial Andrés Bello, Chile.

SCOTT C. / JAFFE D.

1993: ¿Cómo dirigir el cambio en las organizaciones? Grupo Editorial Iberoamérica, México.

SENGE, P.

1992: La quinta disciplina.Ediciones Granica, Barcelona.

TARÍN, L.

1997: El aprendizaje en las organizaciones: de la formación a las organizaciones que aprenden. Alta Dirección. Enero-febrero

TOFFLER, A.

1994: El cambio del poder: Plaza \& Janes Editores, S.A., Barcelona. 